\title{
ASSESSMENT OF KNOWLEDGE, ATTITUDE AND PRACTICE OF HAND HYGIENE AMONG HEALTH CARE WORKERS IN THE AIMSR AND DISTRICT GOVERNMENT HOSPITAL OF CHITTOOR, ANDHRA PRADESH- AN OBSERVATIONAL STUDY
}

\author{
Divya Suguna Jayakar'1, B. Kailasanatha Reddy²
}

${ }^{1}$ Assistant Professor, Department of Microbiology, Apollo Medical College, Chittoor, Andhra Pradesh, India.

${ }^{2}$ HOD, Department of Microbiology, Apollo Medical College, Chittoor, Andhra Pradesh, India.

BBSTRACT
BACKGROUND
As the number of multi-drug resistant bacteria is increasing worldwide, it is essential to know the proper steps of hand washing in
order to protect both the patient and the doctor. This study was under taken in the district hospital to throw light on the existing
hand hygiene practices among the health care workers and to implement certain hand hygiene policies or practices in our hospital.

\section{METHODS}

The study was done at the District Hospital and AIMSR Hospital, Chittoor. As it is a collaboration of both the Government and Apollo Hospitals, the study was done on Apollo employees who were about 100 in all. We used a standard WHO questionnaire which was distributed to the participants along with their consent. The results were analysed and compiled.

\section{RESULTS}

In our study, we found that though the knowledge about hand hygiene is present, their day to day implementation seems to have been lost. We also can see that 17 doctors agreed that hand washing immediately after body fluid contact is not needed. Many also believed that hand washing is not needed before touching a patient even for a physical examination.

\section{CONCLUSIONS}

In conclusion, the following study was done to throw light on such malpractices and to implement proper hand washing practices for the betterment of the patient and the health care worker.

\section{KEY WORDS}

Hand Hygiene, Alcohol Based Hand Rubs, Chlorhexidine Based Hand Rubs, Knowledge, Attitude, Practice

HOW TO CITE THIS ARTICLE: Jayakar DS, Reddy BK. Assessment of knowledge, attitude and practice of hand hygiene among health care workers in the AIMSR and district government hospital of Chittoor, Andhra Pradesh- an observational study. J. Evolution Med. Dent. Sci. 2019;8(25):2012-2017, DOI: 10.14260/jemds/2019/442

\section{BACKGROUND}

Hand hygiene is the age old method of preventing hospital acquired infections in hospitals, long before the advent of hand-rubs and washes. As time progressed, this practice seemed to be a distant dream for many of the health care institutions and this could possibly explain the increase in nosocomial infections in the recent decade. However, we could see that with proper hand washing techniques we can still fight this battle in an effective way. The concept of hand hygiene and antisepsis was introduced by Ignel Semmelweis who demonstrated that cleansing heavily contaminated hands with an antiseptic agent between patient contacts may reduce health-care-associated transmission of contagious diseases more effectively than hand washing with plain soap and water. Even though the procedure is much simple the percentage of compliance among health care workers still remains as low as $40 \%{ }^{[1]}$

'Financial or Other Competing Interest': None.

Submission 03-05-2019, Peer Review 10-06-2019,

Acceptance 17-06-2019, Published 24-06-2019.

Corresponding Author:

Dr. Divya Suguna Jayakar,

Assistant Professor,

Department of Microbiology,

Apollo Medical College,

Murukambattu, Chittoor-517127,

Andhra Pradesh, India.

E-mail: divyashrn@yahoo.co.in

DOI: $10.14260 /$ jemds $/ 2019 / 442$
Hospital acquired infections are a major public health threat throughout the world and a WHO study done showed that the highest percentage of these infections are seen mostly reported from the intensive care units and surgical and orthopaedic wards.[2] Various factors contribute to the non-compliance like lack of knowledge, under staffing and lack of proper hand hygiene protocols. A two week observation was done in an ICU to see the compliance of hand hygiene among the health care workers, the compliance rate was found to be $86.2 \%$ for doctors, $94.0 \%$ for nurses and $76.2 \%$ for other staff.[3] This shows the nurses have a high compliance as they have rigorous training in hand hygiene from the early days of their training. This shows that the doctors are still lagging behind in hand hygiene. In a study done in Istanbul, the compliance of hand hygiene among nurses was $41 \%$ whereas among the doctors it was $32 \% .{ }^{[4]}$ Among the nurses $75 \%$ performed hand hygiene before touching the patient and only about $7 \%$ washed hands before any aseptic procedure. If we see the compliance of hand hygiene among doctors in these two situations it was 55\% before touching the patient and $12 \%$ before aseptic procedure. This data shows us the 'Hawthorn effect' of hand washing as number of nurses and doctors performing hand hygiene in the presence of the patient is more than before an aseptic procedure. The Hawthorn effect is the alteration of behaviour by the subjects of a study due to their awareness of being observed. Hence in a view to assess the knowledge and practice of hand hygiene among the health care workers of AIMSR and District Government Hospital, Chittoor the following study will be under taken. 


\section{Aims and Objectives}

1. To obtain information regarding the knowledge, attitude and practice of hand hygiene among health care workers by questionnaires.

2. To analyse the results to assess the knowledge about hand hygiene among medical staff.

3. To demonstrate the five steps of hand hygiene to the staff and obtain a feedback for the same.

4. To formulate hand hygiene guidelines and regular motivation classes for the staff as a part of hospital infection control policy.

\section{METHODS}

\section{Sample Size}

As our hospital is a collaboration of both the Government and Apollo hospitals, the sample size was taken as 100 which included only the employees from the Apollo hospitals. This included 40 doctors and 40 staff nurses and 20 laboratory technicians.

\section{Type of Study}

Observational study

\section{Duration of The Study}

2 months.

\section{Inclusion Criteria}

All Apollo employees who were doctors, nurses and laboratory technicians working in the AIMSR and District Government Hospital, Chittoor.

\section{Exclusion Criteria}

Nursing students and non-medical staff members.

\section{Method of Data Collection}

A pre-tested WHO questionnaire was used for the data collection. We distributed the questionnaires after obtaining consent using an informed consent form and explaining to the participants the purpose of the study.

\section{Consent}

An informed consent was obtained from the participants and they were assessed using a Knowledge, Attitude and Practice questionnaire.

\section{Statistical Analysis}

The statistical analysis was done separately for doctors, nurses and laboratory technicians using mean average score of knowledge, attitude and practice separately and compared with standard guidelines according to CDC (Center of Disease Control).

\section{RESULTS}

The study was conducted at AIMSR and government Hospital Chittoor. A sample size of 100 health care workers were chosen and among that the number of participants were 52 . Each health care worker was assessed using a questionnaire which contained the WHO questions on hand hygiene. Out of the 52 participants, 15 were laboratory technicians, 17 were doctors and 20 were staff nurses. The data was analysed and depicted by bar diagrams and tables. A total of $75 \%$ of nurses and $65 \%$ of doctors and $53 \%$ of lab technicians agreed that they were trained in hand hygiene at least once in their carrier. Correlating this information with the onward answers to the rest of the questions proves that the health care workers do have sufficient knowledge about the same. Although few questions do not prove this point either. If we assess the knowledge about hand hygiene among doctors, we can see that $65 \%$ of them routinely use an alcohol-based hand rub regularly.

When we see their knowledge about the routes of transmission of germs to the patient 17 of them agreed that hand washing immediately after exposure to body fluids is not needed. This may be due to the availability of alcoholbased rubs which can be used easily. This can also point to the act that because of the busy schedules and commitments towards other patients and lack of time the doctors avoid washing the hands with soap and water.

\begin{tabular}{|c|c|c|c|}
\hline $\begin{array}{l}\text { Sl. } \\
\text { No. }\end{array}$ & Questions & Yes & No \\
\hline 1 & Did you receive any formal training in $\mathrm{HH}$ & $11(65 \%)$ & $6(35 \%)$ \\
\hline 2 & Do you routinely use alcohol-based hand rub & \begin{tabular}{|l|l|}
$12(71 \%)$ \\
\end{tabular} & $6(35 \%)$ \\
\hline 3 & $\begin{array}{c}\text { Which of the following is a main route of cross } \\
\text { transmission? } \\
\text { C ans: health care workers hands when not } \\
\text { clean. }\end{array}$ & $11(65 \%)$ & $6(35 \%)$ \\
\hline 4 & \begin{tabular}{|c|} 
What is the frequent source of germs \\
responsible for health care associated \\
infections? C. ans: Germs already present on or \\
within the patient
\end{tabular} & $1(6 \%)$ & $16(94 \%)$ \\
\hline $5 \mathrm{a}$ & Before touching a patient & $11(65 \%)$ & $6(35 \%)$ \\
\hline $\mathrm{b}$ & Immediately after exposure to body fluids & 0 & $\begin{array}{c}17 \\
(100 \%)\end{array}$ \\
\hline c & $\begin{array}{c}\text { After exposure to the immediate surrounding } \\
\text { of the patient }\end{array}$ & $3(18 \%)$ & $14(82 \%)$ \\
\hline $\mathrm{d}$ & Immediately before clean/ aseptic procedure & $10(59 \%)$ & $7(41 \%)$ \\
\hline 6 & $\begin{array}{l}\text { Which of the following hand hygiene prevents } \\
\text { transmission of germs to the health care } \\
\text { worker? }\end{array}$ & & \\
\hline $\mathrm{a}$ & After touching & & $6(35 \%)$ \\
\hline $\mathrm{b}$ & Immediately after ex & $(47 \%)$ & $7(41 \%)$ \\
\hline c & Immediately before clean/a & 0 & $15(88 \%)$ \\
\hline $\mathrm{d}$ & $\begin{array}{l}\text { After exposure to immediate surroundings of a } \\
\text { patient }\end{array}$ & $5(29 \%)$ & $10(59 \%)$ \\
\hline 7 & $\begin{array}{r}\text { Which of the following stat } \\
\text { based hand rub and hand } \\
\text { and water are }\end{array}$ & & \\
\hline a & $\begin{array}{r}\text { Hand rubbing is more rapic } \\
\text { than hand wa }\end{array}$ & $8(47 \%)$ & $9(53 \%)$ \\
\hline $\mathrm{b}$ & $\begin{array}{r}\begin{array}{r}\text { Hand rubbing cause } \\
\text { han }\end{array} \\
\end{array}$ & $3(18 \%)$ & $14(82 \%)$ \\
\hline c & $\begin{array}{l}\text { Hand rubbing is mor } \\
\text { than ha }\end{array}$ & $3(18 \%)$ & $14(82 \%)$ \\
\hline $\mathrm{d}$ & $\begin{array}{r}\text { Hand washing and hand } \\
\text { to be performed }\end{array}$ & $7(41 \%)$ & $10(59 \%)$ \\
\hline 8 & $\begin{array}{c}\text { What is the minimum time needed for alcohol- } \\
\text { based hand rub to kill most germs on your } \\
\text { hands? C ans; } 20 \text { secs }\end{array}$ & $9(53 \%)$ & $8(47 \%)$ \\
\hline 9 & $\begin{array}{l}\text { Which type of hand hygiene method is } \\
\text { required in the following situations? }\end{array}$ & & \\
\hline 1 & Before palpation of the abdomen & $12(71 \%)$ & $5(29 \%)$ \\
\hline 2 & & & \\
\hline 3 & & $2(12 \%)$ & $15(88 \%)$ \\
\hline 4 & After remor & $5(29 \%)$ & $12(71 \%)$ \\
\hline 5 & & & $10(59 \%)$ \\
\hline 6 & Afte & $15(88 \%)$ & $2(12 \%)$ \\
\hline 10. & $\begin{array}{l}\text { Which of the following should be avoided, as } \\
\text { associated with increased likelihood of } \\
\text { colonization of hands with harmful germs? }\end{array}$ & & \\
\hline $\mathrm{a}$ & Wearing jewellery & $9(53 \%)$ & $8(47 \%)$ \\
\hline $\mathrm{b}$ & Damaged skin & $5(29 \%)$ & $12(71 \%)$ \\
\hline $\mathrm{c}$ & Long nails & $13(76 \%)$ & $4(23 \%)$ \\
\hline d & Regular use of hand cream & 0 & $\begin{array}{c}17 \\
(100 \%)\end{array}$ \\
\hline
\end{tabular}




\begin{tabular}{|c|c|c|c|c|c|}
\hline $\begin{array}{l}\text { Sl. } \\
\text { No. }\end{array}$ & Questions & \begin{tabular}{|c|} 
Yes \\
Total \\
No.=17 \\
\end{tabular} & $\%$ & \begin{tabular}{|c|} 
No \\
Total \\
No.=17 \\
\end{tabular} & $\%$ \\
\hline 1 & $\begin{array}{c}\text { I adhere to correct hand hygiene } \\
\text { practices at all times }\end{array}$ & 13 & $76 \%$ & 4 & $23 \%$ \\
\hline 2 & $\begin{array}{c}\text { Sometimes I have more things to } \\
\text { do than hand hygiene }\end{array}$ & 4 & $23 \%$ & 12 & $71 \%$ \\
\hline 3 & $\begin{array}{c}\text { I have sufficient knowledge about } \\
\text { hand hygiene }\end{array}$ & 16 & $94 \%$ & 1 & $6 \%$ \\
\hline 4 & $\begin{array}{c}\text { Emergencies and other priorities } \\
\text { make hand hygiene difficult at } \\
\text { times }\end{array}$ & 13 & $76 \%$ & 4 & $23 \%$ \\
\hline 5 & $\begin{array}{l}\text { Wearing gloves reduces the need } \\
\text { for hand hygiene }\end{array}$ & 3 & $18 \%$ & 14 & $82 \%$ \\
\hline 6 & $\begin{array}{l}\text { I feel frustrated when others omit } \\
\text { hand hygiene }\end{array}$ & 11 & $65 \%$ & 6 & $35 \%$ \\
\hline 7 & $\begin{array}{c}\text { I am reluctant to ask others to } \\
\text { engage in hand hygiene }\end{array}$ & 5 & $29 \%$ & 11 & $65 \%$ \\
\hline 8 & $\begin{array}{l}\text { Newly qualified staff has not been } \\
\text { properly instructed }\end{array}$ & 9 & $53 \%$ & 7 & $41 \%$ \\
\hline 9 & I feel guilty if I omit hand hygiene & 14 & $82 \%$ & 3 & $18 \%$ \\
\hline 10 & $\begin{array}{l}\text { Adhering to and hygiene practice } \\
\text { is easy in the current set up }\end{array}$ & 11 & $65 \%$ & 6 & $35 \%$ \\
\hline 11 & $\begin{array}{l}\text { I am allergic to hand rubs and } \\
\text { hand washing soaps }\end{array}$ & 0 & $0 \%$ & 17 & $100 \%$ \\
\hline
\end{tabular}

\begin{tabular}{|c|c|c|c|c|c|}
\hline $\begin{array}{c}\text { Sl. } \\
\text { No. }\end{array}$ & Questions & $\begin{array}{c}\text { Yes } \\
\text { (n=20) }\end{array}$ & \% & $\begin{array}{c}\text { No } \\
(\mathbf{n = 2 0})\end{array}$ & \% \\
\hline 1 & $\begin{array}{c}\text { I adhere to correct hand hygiene } \\
\text { practices at all times }\end{array}$ & 13 & 65 & 7 & 35 \\
\hline 2 & $\begin{array}{c}\text { Sometimes I have more things to do } \\
\text { than hand hygiene }\end{array}$ & 12 & 60 & 7 & 35 \\
\hline 3 & $\begin{array}{c}\text { I have sufficient knowledge about } \\
\text { hand hygiene }\end{array}$ & 9 & 45 & 11 & 55 \\
\hline 4 & $\begin{array}{c}\text { Emergencies and other priorities } \\
\text { make hand hygiene difficult at times }\end{array}$ & 10 & 50 & 10 & 50 \\
\hline 5 & $\begin{array}{c}\text { Wearing gloves reduces the need for } \\
\text { hand hygiene }\end{array}$ & 15 & 75 & 5 & 25 \\
\hline 6 & $\begin{array}{c}\text { I feel frustrated when others omit } \\
\text { hand hygiene }\end{array}$ & 10 & 50 & 10 & 50 \\
\hline 7 & $\begin{array}{c}\text { I am reluctant to ask others to engage } \\
\text { in hand hygiene }\end{array}$ & 8 & 40 & 13 & 65 \\
\hline 8 & $\begin{array}{c}\text { Newly qualified staff has not been } \\
\text { properly instructed }\end{array}$ & 19 & 95 & 1 & 5 \\
\hline 9 & I feel guilty if I omit hand hygiene & 12 & 60 & 8 & 40 \\
\hline 10 & $\begin{array}{c}\text { Adhering to and hygiene practice is } \\
\text { easy in the current set up }\end{array}$ & 11 & 55 & 9 & 45 \\
\hline 11 & $\begin{array}{c}\text { I am allergic to hand rubs and hand } \\
\text { washing soaps }\end{array}$ & 7 & 35 & 13 & 65 \\
\hline \multicolumn{5}{|c|}{ Table 3. Attitude of Hand Hygiene Among Nurses n=20 } \\
\hline
\end{tabular}

\begin{tabular}{|c|c|c|c|c|c|}
\hline $\begin{array}{c}\text { Sl. } \\
\text { No. }\end{array}$ & Questions & $\begin{array}{c}\text { Yes } \\
\text { No.=15 }\end{array}$ & \% & $\begin{array}{c}\text { No Total } \\
\text { No.=15 }\end{array}$ & \% \\
\hline 1 & $\begin{array}{c}\text { I adhere to correct hand hygiene } \\
\text { practices at all times }\end{array}$ & 11 & 73 & 4 & 27 \\
\hline 2 & $\begin{array}{c}\text { Sometimes I have more things to do } \\
\text { than hand hygiene }\end{array}$ & 9 & 60 & 6 & 40 \\
\hline 3 & $\begin{array}{c}\text { I have sufficient knowledge about } \\
\text { hand hygiene }\end{array}$ & 9 & 60 & 6 & 40 \\
\hline 4 & $\begin{array}{c}\text { Emergencies and other priorities } \\
\text { make hand hygiene difficult at } \\
\text { times }\end{array}$ & 12 & 80 & 3 & 20 \\
\hline 5 & $\begin{array}{c}\text { Wearing gloves reduces the need } \\
\text { for hand hygiene }\end{array}$ & 13 & 87 & 2 & 13 \\
\hline 6 & $\begin{array}{c}\text { I feel frustrated when others omit } \\
\text { hand hygiene }\end{array}$ & 9 & 60 & 6 & 40 \\
\hline 7 & $\begin{array}{c}\text { I am reluctant to ask others to } \\
\text { engage in hand hygiene }\end{array}$ & 1 & 7 & 14 & 93 \\
\hline 8 & $\begin{array}{c}\text { Newly qualified staff has not been } \\
\text { properly instructed }\end{array}$ & 10 & 67 & 5 & 33 \\
\hline 9 & I feel guilty if I omit hand hygiene & 7 & 14 & 8 & 53 \\
\hline 10 & $\begin{array}{c}\text { Adhering to hand hygiene practice } \\
\text { is easy in the current set up }\end{array}$ & 7 & 14 & 8 & 53 \\
\hline 11 & $\begin{array}{c}\text { I am allergic to hand rubs and hand } \\
\text { washing soaps }\end{array}$ & 1 & 7 & 14 & 93 \\
\hline Table 4. Attitude of Hand Hygiene Among Lab. Technicians $\boldsymbol{n}=\mathbf{1 5}$ \\
\hline
\end{tabular}
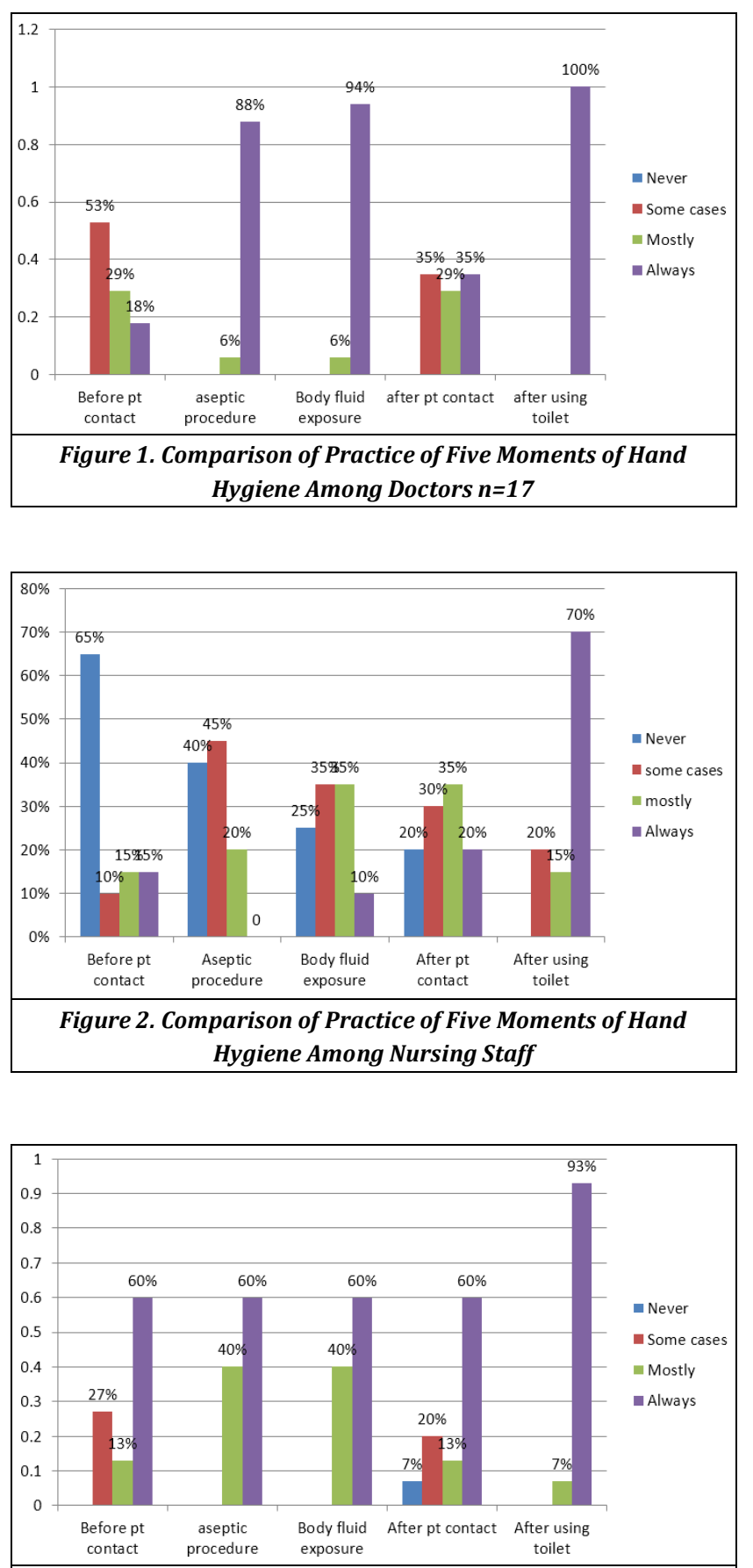

Figure 3. Comparison of Five Moments of Hand Hygiene Among Lab. Technicians $n=15$

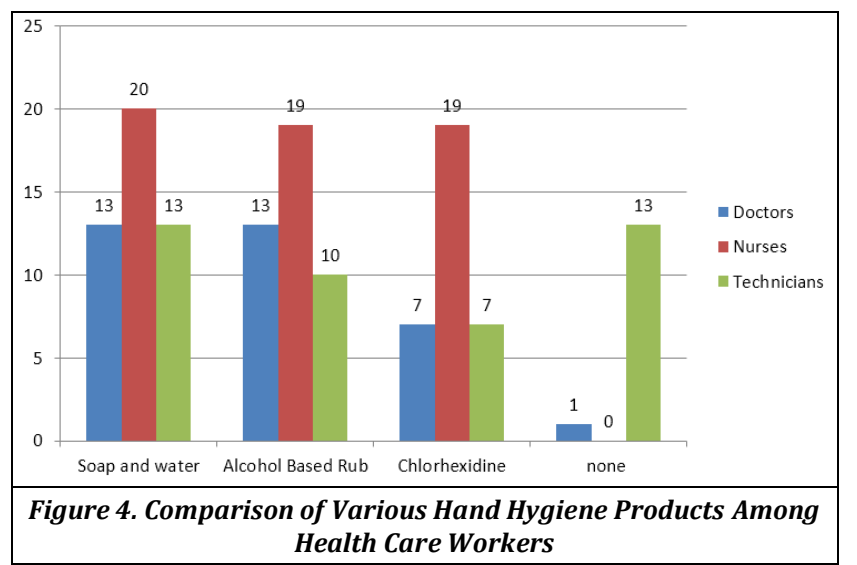


Moving on to assess the practice of hand hygiene among the doctors it is seen that the five moments of and hygiene was carried out almost always and few of the doctors agreed that mostly they followed the five moments in spite of their busy schedule. The same is depicted in the bar diagram (Fig. 1)

Here we can see that about $53 \%$ of doctors washed hands before patient contact in some cases, this may depend upon the infectivity of the patient. E.g.: before wound debridement $88 \%$ agreed that they always followed hand hygiene before an aseptic procedure, and $94 \%$ will wash their hands after exposure to body fluids. Although these findings are quiet encouraging these five most moments in hand hygiene should be assessed on the spot to get an exact knowledge of the current scenario.

In the above diagram we can see that $65 \%$ of nurses do not wash hands before patient contact and that $45 \%$ of them wash hands before an septic procedure. This data reveals the ignorance of the nursing staff and their casual attitude towards the patients. But $70 \%$ of them agreed that they wash hands after using the toilet which is a measure of basic hygiene. $35 \%$ mostly wash hands after patient contact and only $10 \%$ wash hands routinely after body fluid exposure. The reason for such a vast difference may be due to the use of alcohol-based hand rubs which is believed to kill almost all the germs but in reality, it is not so. The nurses were found to use these hand rubs as they are easy to use and does not need soap and water.

$19 \%$ of the nurses, $13 \%$ of the doctors and $10 \%$ of the technicians use alcohol based hand rubs for hand hygiene. This low percentage may suggest that the availability of the hand rub is very much limited. Some hospitals insist on bedside hand rubs for each patient, but in our hospital were usually the patient belongs to poverty line or below the affordability is very less. Alcohol based hand-rub is recommended for hand decontamination in all clinical settings apart from visibly soiled hands. Alcohol hand-rub uses alcohol instead of water. In contrast to the mechanical (Friction) removal of flora in hand washing, alcohol works by killing the flora. Alcohol hand-rub differs from hand washing because it acts on the microorganisms by denaturing their proteins and thus has the ability to eradicate all transient flora and most resident flora. It also takes less time than hand washing, between 15 to 30 seconds. However a study done among $340 \mathrm{HCW}$ in India showed that ABH rubs were the most common agent used for hand hygiene and its compliance was $37 \%$ for nurses and $28 \%$ for doctors.[5] This surely shows that $\mathrm{ABH}$ rubs are the best agent for hand sanitation because of its ease in using.

The HCW should adopt only one product for hand hygiene but never both. This will lead to skin irritation and dryness and ultimately lead to cross infection. Hence after washing application of lotions to moisturize the skin and prevent it from dryness should be done. $7 \%$ of the doctors and technicians use chlorhexidine hand wash for hand hygiene which is even more effective than alcohol based rub. 18\% of doctors agree that disposable towels are available for drying the hands after hand washing. $29 \%$ of them also agree that hand washing sinks are present in the ICUs and wards and they are easily available for washing. $60 \%$ of nurses agree that sinks are present and $70 \%$ say they are easily available for washing. A study done in New Delhi showed that $44 \%$ of doctors reported that sinks were not available at the point of care. In the nursery and neonatal ICU, the nurse to patient ratio was 1:6 to $1: 7$. Elbow operated deep sinks were seen but not easily accessible.[6]

This data have to be cross checked by conducting a direct observational study in our hospital in all the ICUs and wards. Even though hand drying is done by a hand dryer using a disposable towel seems to be more effective. Hand dryers make the hands more dry whereas towels preserve the moisture in the skin. Care should be taken to change the towels daily and to have adequate supply of the towels.

\section{DISCUSSION}

\section{Knowledge Regarding Hand Hygiene Among Doctors}

Though they do agree that washing hands just before an aseptic procedure is necessary (59\%) they do not seem to understand that hand washing is needed even before they touch a patient even for a physical examination (35\%). This gross variation maybe due to the lack of time and that some of the staff may consider hand washing a waste of time. When we compare this data with a study done in Puducherry, we can see that there is moderate knowledge about hand hygiene among doctors compared with the nursing staff. The nursing staff seemed to have a better knowledge about hand hygiene.[1] A study done among the doctors and nurses in the ICU in a hospital in Saudi Arabia we can see that the hand washing non-compliance is more prevalent among doctors than the nurses.[7] This finding is also consistent with our study and proves that the physicians do not adhere to hand hygiene. Patient surroundings play a vital role in spreading the harmful germs to the health care worker. Hence they are equally at risk when they attend to the patient like intubation in emergency situations, cardiac monitors and a simple stethoscope, $59 \%$ of the doctors agree that there is no transmission of germs after exposure to the surroundings of the patient and $53 \%$ of them agreed that there is transmission of germs only after touching the patient. According to Collins [8] hand hygiene should be considered before invasive procedures, after contact with contaminated devices or materials, and with high risk, infectious patients. Moreover, Kampf claimed that hand hygiene should be advocated before beginning work, at the end of work, and after visiting the rest room (Toilet). A study done in Karad shows that transient flora, on the other hand, colonise the superficial skin layers for a short time. The hands of HCWs are often contaminated with transient flora by direct contact during daily patient care activities, environments or equipment.[2] Even though there are convincing evidences that the patient surroundings do carry harmful germs like MRSA etc, the understanding is still lacking among the doctors in our study. Numerous studies have shown that $\mathrm{HH}$ practices are employed more frequently 'after' rather than 'before' patient contact. Further data are tabulated in table no 1.

\section{Attitude of Doctors Towards Hand Hygiene}

If we assess the attitude of the doctors on hand hygiene, then we can see that $76 \%$ adhere to correct hand hygiene practices and $94 \%$ claimed that they had sufficient knowledge about hand hygiene. Although these are on paper, we cannot find any correlation between the knowledge and the attitude of the doctors. When we compare this with the attitude of 
nurses then we can see that $65 \%$ of them adhere to the correct hand hygiene practices and $55 \%$ of them agree that they do not have proper understanding about hand hygiene. When this is compared with the previous studies done in South India it shows that the attitude is poor among the medical staff compared to the nursing staff.[1] Only 51\% of medical doctors felt that they had sufficient knowledge about hand hygiene compared to nursing staff (93\%). Hence based on the above study we can correlate and show that the results obtained in our study is similar. This situation is the same when compared with western studies. The results of the attitude of the doctors, nurses and technicians are tabulated in table 2,3 and 4 .

\section{Attitude of Nurses and Technicians Towards Hand Hygiene}

When we compare the attitude of hand hygiene among the nurses and technicians, we can see that $73 \%$ of the technicians adhere to correct hand hygiene practices and $60 \%$ agreed that they have sufficient knowledge about hand hygiene. Even though the percentage is more than that of nurses the actual practice does not seem to reflect this fact. There are no known studies about the attitude of hand hygiene among lab technicians. $87 \%$ of the technicians believed that wearing gloves reduces the need for hand washing compared to $75 \%$ of the nurses. Wearing gloves does not provide a barrier for hand washing, in fact washing hands after degloving the hands is more advisable according to CDC guidelines. $95 \%$ of the nurses agreed that the newly qualified nurses do not have sufficient knowledge about hand hygiene compared to $67 \%$ of the technicians who agreed the same. This shows that there exists a gap between the new staff and senior staff as it is the sole responsibility of the seniors to teach the new staff. Similar gap does not seem to exist too much among the technicians. This is an area which shows us that we need to set up an infection control team which will motivate and teach the staff about hand hygiene from time to time. Another reason for not practicing hand washing is allergy to the hand rubs which was less among doctors and $35 \%$ among nurses and $7 \%$ among technicians. This is just framed as an excuse for not to wash hands as the commercially available hand rubs are completely skin friendly and available in gentle odours.

Almost 35\% of the doctors believe that washing hands after patient contact is a must. When we compare our data with the studies done in South India we can see that the practice of hand hygiene is poor among medical team compared to the nursing staff (Medical-73\%, nursing-57\%) and only $3 \%$ of the doctors showed good hand hygiene practice. ${ }^{[1]}$ Furthermore a study done in Pune showed that more that $80 \%$ of the doctors had knowledge about the five moments of hand hygiene but it was not put into actual practice. A total of $91.48 \%$ participants answered "always" in response for actually performing hand hygiene (practice) after a body fluid exposure risk (Moment 3 ), but for the rest of the moments (Moment 1, 2, 4, 5) the response was poor $(<70 \%)$. ${ }^{[9]}$

\section{Five Moments of Hand Hygiene}

When we compare the practice of the five moments of hand hygiene with the nursing staff it is seen that $65 \%$ of the nursing staff do not practice hand washing before patient contact compared to $15 \%$ of nurses who always practice hand hygiene. $40 \%$ never washed hands before an aseptic procedure and $20 \%$ never washed hands after patient contact. Whereas $70 \%$ agreed that they wash hands after using the toilet. This data clearly shows the ignorance of the nursing staff members in this area of hygiene. Since washing hands after using the toilet is a concern for the individual, they do not seem to have a proper knowledge about the five moments of and washing. Similar data was noted in a study done by Rynga et al that the nurses' believed that it is not important to practice hand hygiene with every patient $(25.6 \%)$, or when their hands are not visibly soiled (25.6\%).[6] As a remedy measure we can conduct camps and hand hygiene seminars for the nursing staffs both newly joined and the seniors who will take up an active role as hospital infection control nurses. The comparison is as shown in fig 2.

A study done in New Delhi showed that the majority of them self-reported that they knew about the six steps of $\mathrm{HH}$ (96\%) and five moments for HH (89.3\%). However only $47.9 \%(35 / 75)$ knew the right duration of $\mathrm{HH}$ by alcohol hand rub (20 seconds) and 13.3\% (10/75) had knowledge that all five moments of $\mathrm{HH}$ are equally important[6] when we compare this data with our data we can see that the knowledge of the five moments of hand hygiene is very poor among nurses $(20 \%)$ and technicians $(60 \%)$ when compared to doctors(88\%). This can be achieved by motivating the staff by displaying posters, and role modelling and peer pressure. This was found to be useful in other studies and contributed to about $8 \%$ of the staff.

\section{Five Moments of Hand Hygiene Among Nurses and Technicians}

When we compare the five moments of hand hygiene of the technicians with the nurses, we can see that $60 \%$ of them always wash hands before patient contact, before an aseptic procedure, after body fluid exposure. $7 \%$ of the technicians agreed that they do not wash hands after patient contact. This may be due to the availability of alcohol based hand rubs which makes the hand hygiene easy. As lab technicians they are exposed to all type of patients which may pose a serious risk of transfer of pathogens from the patient to themselves and even vice versa. When compared with nurses we can see that there is a lot of variation among the two groups.

\section{Various Hand Hygiene Products Used}

On comparing the various products used for hand washing we can see from fig 4 that $20 \%$ of nurses used soap and water for hand washing and $13 \%$ of doctors and technicians used the same during work. A direct observational study done in Government hospital in Chandigarh showed that the product used like (Liquid soap \& alcohol-based solution) was noted from the stock registers/record books of the materials issued/indented in the wards. It was found that one soap cake (120 gm.) is worth for 40 hand washings, while liquid alcohol rub is worth for 334 (Approx.) hand washings/bottle $(500 \mathrm{~mL})$. The purchase done by staff was also taken into account. By this method the average usage of these products was found out and was found to be $96.04 \%$ with alcohol rubs and $3.96 \%$ with soap.[3] On comparing this data with our study we can see that hand washing using soap and water is the most preferred product of hand hygiene in our hospital. It 
may also include the cost criteria where Alcohol based rubs are more costly.

In the same study it was found out that there was low compliance among the doctors as using soap and water is tedious and time-consuming method. The number of Hospital acquired infections were more when compared to Alcohol based rubs, and is effective only if it is practiced for the recommended time and method. To promote hand hygiene among patients a hospital in the United States of America it was proposed to fit the ABH rubs to the gowns of the patient, by doing this they would remember to clean their hands every time.[10] Knowledge about hand hygiene products should be explained to the staff in their own language and give them the choice to follow one product only. A study in Pune showed that Knowledge about the differences between ABHR and hand washing with soap and water was poor overall amongst the study population[9]

Among the rural parts of India, the most common product used are soap and water (63-82\%), followed by spirit or Alcohol based hand rubs which was highest in the OTs (54\%). Other optional materials included 'Only water', 'Water and antiseptic solution' and 'Water and liquid soap. This study also showed the HCWs were willing to learn about hand hygiene in the future and willing to implement the same [11]. In resource limited countries the WHO manual on hand hygiene is not followed and a study shows that $17 \%$ of the doctors agreed that they were not aware of the manual[12]

\section{CONCLUSIONS}

Our hospital needs a proper hospital infection control team which should consist of a senior nurse as infection control nurse and a microbiologist. Periodical rounds should be conducted in the wards and ICUs to ensure the cleanliness and carrier nursing procedures by the other staffs. When we see the feedback obtained from our study, it appears that education of technicians and nurses is required. This can be done by a demonstration of hand washing live or by using videos and seminars conducted in their own language. Another group which are equally at risk and ignorant are the house keeping staff. As they have an active role in waste management. We should educate them on the need for hand washing after handling infectious waste. A hand washing course can be conducted for the doctors, nurses who do not seem to have a proper understanding of hand hygiene according to the data obtained.

\section{REFERENCES}

[1] Arthi E, Abarna V, Bagyalakshmi R, et al. Assessment of knowledge, attitude and practice of hand hygiene among nursing and medical students in a tertiary care hospital in Puducherry, India. International Journal of Contemporary Medical Research 2016;3(4):1203-6.
[2] Shinde MB, Mohite VR. A study to assess knowledge, attitude and practices of five moments of hand hygiene among nursing staff and students at a tertiary care hospital at Karad. International Journal of Science and Research (IJSR) 2014;3(2):311-21.

[3] Sharma R, Sharma M, Koushal V, Hand washing compliance among healthcare staff in Intensive Care Unit (ICU) of a multispecialty hospital of north India. Journal of Hospital Administration 2012;1(2)27-33.

[4] Karaaslan A, Kadayifci KE, Serkan A, et al. Compliance of healthcare workers with hand hygiene practices in neonatal and pediatric intensive care units: overt observation. Article ID 306478, Interdisciplinary Perspectives on Infectious Diseases 2014;2014:1-5.

[5] Sureshkumar D, Ramasubramanain V, Abdulgafur K, et al. Hand hygiene compliance in India. BMC Proceedings 2011;5(Suppl 6):P259.

[6] Rynga D, Kumar S, Gaind R, et al. Hand hygiene compliance and associated factors among health care workers in a tertiary care hospital: self-reported behaviour and direct observation. Int J Infect Control 2017;13(1):1-9.

[7] Mahfouz AA, El Gamal MN, Al-Azraqi TA. Hand hygiene non-compliance among intensive care unit health care workers in Aseer Central Hospital, south-western Saudi Arabia. International Journal of Infectious Diseases 2013;17(9):e729-e32.

[8] Collins F, Hampton S. Hand-washing and methicillinresistant staphylococcus aureus. British Journal of Nursing 2005;14(13):703-7.

[9] Vaishnav B, Bamanikar A, Dasgupta S, et al. Asepticclinical hand hygiene knowledge survey amongst health care workers in a tertiary care hospital in Western India. Int J Res Med Sci 2016;4(9):4176-82.

[10] Ellingson K, Haas JP, Aiello AE, et al. Strategies to prevent healthcare-associated infections through hand hygiene. Infection Control and Hospital Epidemiology 2014;35(8):937-60.

[11] Diwan V, Gustafsson C, Klintz RS, et al. Understanding healthcare workers self-reported practices, knowledge and attitude about hand hygiene in a medical setting in rural India. PLoS One 2016;11(10):e0163347.

[12] Anwar MA, Rabbi S, Masroor M, et al. Self-reported practices of hand hygiene among the trainees of a teaching hospital in a resource limited country. J Pak Med Assoc 2009;59(9):631-4. 